This item was submitted to Loughborough's Research Repository by the author.

Items in Figshare are protected by copyright, with all rights reserved, unless otherwise indicated.

\title{
Modelling the photo-Fenton oxidation of the pharmaceutical paracetamol in water including the effect of photon absorption (VRPA)
}

\section{PLEASE CITE THE PUBLISHED VERSION}

http://dx.doi.org/10.1016/j.apcatb.2014.11.023

\section{PUBLISHER}

(C) Elsevier

VERSION

AM (Accepted Manuscript)

\section{PUBLISHER STATEMENT}

This work is made available according to the conditions of the Creative Commons Attribution-NonCommercialNoDerivatives 4.0 International (CC BY-NC-ND 4.0) licence. Full details of this licence are available at: https://creativecommons.org/licenses/by-nc-nd/4.0/

\section{LICENCE}

CC BY-NC-ND 4.0

\section{REPOSITORY RECORD}

Reina, A. Cabrera, L. Santos-Juanes, J.L. Garcia Sanchez, J.L. Casas Lopez, M.I. Maldonado Rubio, Gianluca Li Puma, and J.A. Sanchez Perez. 2015. "Modelling the Photo-fenton Oxidation of the Pharmaceutical Paracetamol in Water Including the Effect of Photon Absorption (VRPA)". figshare. https://hdl.handle.net/2134/19063. 
Modeling the photo-Fenton oxidation of the pharmaceutical paracetamol in water including the effect of photon absorption (VRPA)

Cabrera Reina A. a,b , Santos-Juanes L. ${ }^{\mathrm{a}, \mathrm{b}}$, García Sánchez J.L. ${ }^{\mathrm{a}, \mathrm{b}}$, Casas López

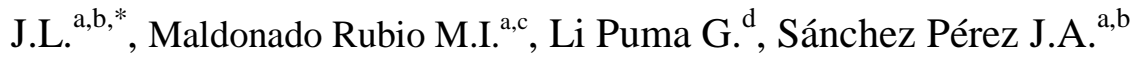

${ }^{a}$ CIESOL, Joint Centre University of Almería-CIEMAT, Almería, Spain.

${ }^{\mathrm{b}}$ Chemical Engineering Department, University of Almería, Spain.

c Plataforma Solar de Almería (CIEMAT), 04200 Tabernas, Almería, Spain ${ }^{\mathrm{d}}$ Environmental Nanocatalysis \& Photoreaction Engineering, Department of Chemical Engineering, Loughborough University, United Kingdom.

*Corresponding author: Chemical Engineering Department, University of Almería, 04120 Almería, Spain. Tel.: +34 950015832; fax: +34 950015484. e-mail address: jlcasas@ual.es (Casas López J.L.). 


\section{Abstract}

A new model is proposed for the photo-Fenton oxidation of water contaminants including the effect of photon absorption (volumetric rate of photon absorption, VRPA), the effect of the geometry of the reactor and the illuminated volume to total volume ratio $\left(R_{i}\right)$ in the reaction system. Fe(III) was found to be the main species in the aqueous solution responsible for photon absorption provided that hydrogen peroxide was not totally consumed. Paracetamol was used as model pollutant at a concentration of $1 \mathrm{mM}$ to validate the model. The illuminated part of the raceway reactor configuration (total length of $80 \mathrm{~cm}$ ) was operated at two liquid depths $(5.0$ and $2.5 \mathrm{~cm})$ equivalent to two irradiated reactor volumes ( 2 and $1 \mathrm{~L}$ ) and using $R_{i}$ ratios in the range $0.30-0.65$, which changed the dark reactor volume. These values are commonly found in photo-Fenton pilot plants for water treatment and purification. The model successfully fitted the temporal evolution of the dissolved oxygen $\left(\mathrm{O}_{2}\right)$ and the hydrogen peroxide $\left(\mathrm{H}_{2} \mathrm{O}_{2}\right)$ concentrations and the evolution of the total organic carbon (TOC) in solution in both reactor geometries and for different illuminated volume to total volume ratios. The model can be easily extended to model other water contaminants and provides a robust method for process design, process control and optimization.

Keywords: photo-Fenton, modeling, VRPA, paracetamol, photoreactor. 
Advanced oxidation processes (AOPs) which are based on the production of highly reactive hydroxyl radicals are effective methods for the degradation and mineralization of recalcitrant contaminants in water and wastewater [1]. Amongst these, AOPs driven by the absorption of photons such as heterogeneous photocatalysis with organic sensitizers and/or semiconductor oxides (mainly $\mathrm{TiO}_{2}$ ) and the photo-Fenton process [35], can be powered by solar light irradiation. Obvious technological and environmental benefits [2] for these AOPs include a net cost reduction of the treatment process and the utilization of a green and sustainable source of energy.

The photo-Fenton process entails the reaction of iron salts and hydrogen peroxide in the presence of UV-vis radiation, which primarily produces hydroxyl radicals while photocatalytically regenerating $\mathrm{Fe}^{3+}$ to $\mathrm{Fe}^{2+}$. The optimum $\mathrm{pH}$ is 2.8 [5] and to prevent the precipitation of the dissolved iron salts, the $\mathrm{pH}$ should be less than 4 . Several scientific and technological aspects of the photo-Fenton process have been thoroughly studied at both laboratory and pilot-plant scale including: the type and nature of contaminants, the impact of the iron species, hydrogen peroxide and interfering species, methods for heterogenization and recovery of the catalyst and the economics of the process [6-9]. Despite this extensive body of knowledge on the photo-Fenton process, the mathematical modeling of the treatment process is still under development, which contrasts with other AOPs. Only a few models have been proposed using a simplified elementary reaction mechanisms or empirical approaches [10-14]. The complexity of the chemical reactions involved and the evolution of the organic matter present during the process are probably the most important reasons.

Photo-catalytically generated radicals can react with organic matter, with hydrogen peroxide or with other radicals. These parallel reactions in some cases generate oxygen, whilst others consume oxygen. Therefore, changes in the reaction dynamics of the photo-Fenton process are reflected by the evolution of the concentration of dissolved oxygen $\left(\mathrm{O}_{2}\right)$, becoming a robust and easily measurable indicator to follow the efficiency of the photo-Fenton process [15]. The modeling and monitoring of the evolution of dissolved oxygen during a photo-Fenton reaction is also important to design process control strategies based on reactant dosage [16-17]. 
The application of the photo-Fenton reaction process for industrial water treatment requires accurate modeling and scale-up considerations. In photo-Fenton reactor scaleup, remarkable differences often exist in the illuminated volume to total volume ratio $\left(R_{i}\right)$ between laboratory, pilot and industrial plants, a parameter which has still not been fully investigated. Additionally, the effects of irradiance and photon absorption on process performance have not been widely studied. This analysis requires the use of detailed expressions regarding the relationship between reactor geometry and UV radiation distribution and the calculation of the local (LVRPA) and the volumetric rate (VRPA) of photon absorption [18].

In this study, we address the above deficiencies by proposing a new model for the photo-Fenton mineralization of water contaminants which includes the effect of the volumetric rate of photon absorption in the illuminated region of the reactor (VRPA) and the influence of the illuminated volume to total volume ratio $\left(R_{i}\right)$ and liquid depth. These parameters are shown to have a significant impact on the global mineralization kinetics of the dissolved organic matter in an experimental raceway photoreactor.

\section{Materials and methods}

\subsection{Photochemical reactor}

The photoreactor, built in polyvinyl chloride (commonly abbreviated PVC), had flat raceway geometry. It was placed inside a SunTest CPS+ solar box and was irradiated from above by means of a Xenon lamp (300-800 nm). The distance from the lamp to the bottom of the reactor was $11 \mathrm{~cm}$. The solar box included a photodiode and a control system which electronically controlled the irradiance to the set point. In addition, the UV irradiance reaching the surface of the liquid was monitored inside the solar box with a portable radiometer (PMA2100 - Solar Light Company) with a spectral response range from 320 to $400 \mathrm{~nm}$. The power of the lamp was varied to provide different levels of irradiance to the water. The liquid depth and the liquid volume in the raceway photoreactor were either $5 \mathrm{~cm}$ and $2 \mathrm{~L}$ of liquid or $2.5 \mathrm{~cm}$ and $1 \mathrm{~L}$ of liquid. The other reactor dimensions were $20 \times 20 \mathrm{~cm}$ (Figure 1). The reactor was operated in a total recirculation mode in which the liquid recirculated through an external well-mixed tank, which was kept in the dark. The irradiated volume to total (dark + irradiated) volume ratio $\left(R_{i}\right)$ was varied by changing the volume of liquid in the recirculation system. The $\mathrm{pH}$ and dissolved oxygen were continuously monitored with CRISON 5335 and 6050 
probes, respectively. The probes were placed inside two flow cells at the raceway reactor exit, outside the solar box. The temperature of the liquid in the system was measured with a CRISON 6050 probe and controlled at $30^{\circ} \mathrm{C}$. The $\mathrm{pH}$, dissolved oxygen concentration and temperature probes were connected to a LabJack ${ }^{\circledR} \mathrm{U} 12$ data acquisition card which was interfaced by DAQfactory ${ }^{\circledR}$ software for continuous data acquisition and monitoring. Aqueous samples from the reaction system were collected from the well-mixed recirculation tank through a sampling port at the following times: 0, 5, 15, 30, 45, 60, 75, 90, 105 and 120 min.

\subsection{Photochemical reactions and analytical methods}

High purity acetaminophen (paracetamol) and hydrogen peroxide (30\%) were supplied by Sigma-Aldrich. Sulphuric acid (95-97\%) was obtained from J. T. Baker and ferrous sulphate (99\%) from Fluka. The water matrix used was Milli-Q grade. Paracetamol, often found in surface water and wastewater effluents [19], was chosen as the model contaminant for the photo-oxidation experiments. The initial concentration of paracetamol was $1 \mathrm{mM}$, which corresponds to $8.33 \mathrm{mM}$ TOC. The other operating conditions were: $17.7-26.5 \mathrm{mM} \mathrm{H}_{2} \mathrm{O}_{2}, 0.36 \mathrm{mM} \mathrm{Fe}(\mathrm{II})$ and $32 \mathrm{~W} \mathrm{~m}^{-2}$ of irradiance. The treatment was carried out under acidic $\mathrm{pH}$ (2.8). The effect of the irradiated volume to total volume ratio, $R_{i}$, on the observed photoreaction kinetics was studied for values equal to $0.30,0.45$ and 0.65 . The liquid depth and the reactor volume were normally set to $5 \mathrm{~cm}$ and $2 \mathrm{~L}$ respectively, except for selected experiments aimed at investigating the effect of photon absorption in the reactor in which the irradiated reactor volume was lowered to $1 \mathrm{~L}$ by changing the liquid depth to $2.5 \mathrm{~cm}$. The aqueous samples collected from the reactor at regular intervals were filtered through $0.45 \mu \mathrm{m}$ nylon filters (Millipore Millex-HN) prior to further analyses. The decontamination process was followed by measuring the decrease in the total organic carbon (TOC) for the samples using a Shimadzu- $\mathrm{V}_{\text {CHP }}$ TOC analyzer which was fitted with an autosampler system. The residual hydrogen peroxide in solution was measured with the ammonium metavanadate colorimetric method proposed by Nogueira et al. 2005 [20]. The concentration of iron species in the water was determined by the ophenanthroline standardized spectrometric procedure (ISO 6332). Absorbance measurements were carried out with a Hach Lange DR 5000 spectrophotometer. 


\subsection{Radiation field model, LVRPA and VRPA}

The radiation field incident to the liquid free surface was simulated as parallel rays normal to the reactor surface [21-22] to simplify the radiation field in the reactor in only one-dimension in space. As a consequence, the level of irradiance in the liquid could only vary with the depth from the surface [21]. The extent of absorption of radiation in the photo-Fenton reaction system investigated resulted from the combined effect of the concentration of the species in solution (Fe(III), Fe(II), $\mathrm{H}_{2} \mathrm{O}_{2}$, paracetamol and the transformation products) and the corresponding values of the molar absorption coefficients. Considering the concentrations of these species in the reaction system and their molar absortion coeffcients, Fe(III) in solution was dominant for the absorption of the incident radiation. Hydrogen peroxide and ferrous ion do not absorb radiation above $300 \mathrm{~nm}$ [18]. The absorption of paracetamol and of the transformation products during the photo-Fenton reaction was found to be negligible in comparison to the absorbance of Fe(III). The UV-vis absorption spectra of aqueous Fe(III) solutions at pH equal to 2.8 were, therefore, evaluated (Figure 2) and the spectral-averaged specific absorption coefficient $k\left(\mathrm{mM}^{-1} \mathrm{~m}^{-1}\right)$ of solution species was determined, Eq. 1.

$$
\kappa=\frac{\int_{\lambda_{\min }}^{\lambda_{\max }} k_{\lambda} I_{\lambda} d \lambda}{\int_{\lambda_{\min }}^{\lambda_{\max }} I_{\lambda} d \lambda} \cong \frac{\sum_{\lambda \min }^{\lambda \max } k_{\lambda} I_{\lambda}}{\sum_{\lambda \min }^{\lambda \max } I_{\lambda}}
$$

where $I_{\lambda}$ is the lamp power at the corresponding wavelength $\left(\mathrm{W} \mathrm{m}^{-2}\right.$ ) which was supplied by the manufacturer, and $k_{\lambda}$ is the specific absorption coefficient of the solution at the corresponding wavelength $\left(\mathrm{mM}^{-1} \mathrm{~m}^{-1}\right)$ determined from the results in Fig. 2 [18].

For the purpose of this study the wavelength limits in Eq. 1 were those corresponding to UV radiometer (320-400 nm) where the radiant energy was measured, although the integration should be extended to $320 \mathrm{~nm}$, the absortion edge of Fe(III). The spectralaveraged specific absorption coefficient $\kappa$ for Fe(III) acidic solutions in ultrapure water was $125 \mathrm{mM}^{-1} \mathrm{~m}^{-1}$.

The local volumetric rate of photon absorption (LVRPA) at a specific depth in the photochemical reactor was determined by a modified Beer-Lambert equation

$$
\text { LVRPA }=\kappa \cdot C \cdot I_{0} \cdot 10^{-\mathrm{k} \cdot \mathrm{C} \cdot \mathrm{x}}, \mathrm{W} \mathrm{m}{ }^{-3}
$$


where $C$ is the concentration of iron in solution $(\mathrm{mM}), I_{0}$ is the irradiance $\left(\mathrm{W} \mathrm{m}^{-2}\right)$ at the reactor surface and $x$ is the spatial coordinate $(\mathrm{m})$ in the transversal direction from the surface of the liquid to a specified liquid depth. The total radiant power absorbed in the reactor was averaged over the liquid depth (VRPA) by integrating the LVRPA (Eq. 3) and multiplying by the reactor free surface, $S_{\text {reactor }}\left(\mathrm{m}^{2}\right)$ :

$V R P A=S_{\text {reactor }} \int_{0}^{x} \kappa \cdot C \cdot I_{0} \cdot 10^{-k \cdot C \cdot x} d x, \mathrm{~W}$

The photo-Fenton iron cycle is represented by the reaction of $\mathrm{Fe}(\mathrm{II})$ with hydrogen peroxide generating the hydroxyl radical and $\mathrm{Fe}(\mathrm{III})$; and by the photochemical reduction of Fe(III) with absorbed photons yielding another hydroxyl radical and Fe(II), which completes the iron catalytic ideal cycle. The rate of hydroxyl radical and $\mathrm{Fe}(\mathrm{II})$ formation varied with position in the reactor, however, the overall rate of formation of these two species from the photochemical reaction is a function of the VRPA, the radiant power absorbed in the reactor.

\subsection{Photo-Fenton Chemistry and Reaction Kinetic Model}

The elementary reactions of the photo-Fenton mechanism considered in the kinetic model, the elementary rate laws and the mass balances for each of the participating reacting species are shown in Table 1. The species included in the reaction mechanism are: $\mathrm{Fe}(\mathrm{II}), \mathrm{Fe}(\mathrm{III}), \mathrm{H}_{2} \mathrm{O}_{2}, \mathrm{R}$ (all radicals are considered as a single type although hydroxyl radical can be considered the predominant radical specie), dissolved oxygen $\left(\mathrm{O}_{2}\right)$ and three different types of organic matter, $\mathrm{M}, \mathrm{MX}$ and $\mathrm{MX}_{2}$ (representing the original compound and two groups of oxidized transformation products before mineralization to $\mathrm{CO}_{2}$ ). The lumping of the oxidized transformation products in groups is related to the prediction capability of the model. The use of a lower number of intermediate groups considerably diminishes the model prediction accuracy, while the use of a higher number does not improve it.

The proposed photo-Fenton mechanism comprises three types of reactions: i) the photoFenton catalytic cycle (Reactions 1 and 2) and radical formation, ii) Reactions 5-9 of efficient radicals consumption (mineralization/oxidation reactions) and iii) Reaction 3 and 4, which represent the inefficient consumption of radicals to yield molecular oxygen. Oxygen can be generated by the reaction between two radicals or between a 
radical and hydrogen peroxide. Note that the Dorfman mechanism, responsible for oxygen consumption during the first stages of mineralization, is reflected by the photoFenton model (Reaction 5) [23]. Regarding the oxidation/mineralization reactions (Reactions 5-9), only the partially oxidized organic matter can be completely mineralized with the corresponding $\mathrm{CO}_{2}$ release. TOC can be calculated as the sum of $\mathrm{M}, \mathrm{MX}_{1}$ and $\mathrm{MX}_{2}$. The use of TOC as a global contaminant concentration parameter allows the model to be adapted to other contaminants or mixture of contaminants.

The dynamic model presented in this study is based on mass balances for the most relevant components of the photo-Fenton reaction process operated in batch mode with external recirculation through a well mixed vessel. However, the model can be extended to other reactor operating conditions such as the continuous flow operation, by making appropriate changes in the mass balances. The terms in the mass balances involving the photochemical reaction (Reaction 2) include the illuminated volume to total volume ratio $R_{i}$ since this reaction can be carried out only under irradiation.

The dynamics of the dissolved oxygen uptake in the water is considered in the mass balance (Eq. 20) through the overall volumetric gas-liquid mass transfer coefficient $\left(K_{L} a\right)$ which represents an additional model parameter [24]. Furthermore, another three additional parameters are included in the oxygen mass balance, which can be considered equivalent to the stoichiometric coefficients of the reaction mechanism.

\subsection{Numerical issues and assays}

The experiments carried out in this study were divided into two groups for parameter identification (2/3 of the assays) and model validation (1/3 of the assays). The process model parameters were obtained by implementing a Monte Carlo approach in MATLAB $^{\circledR}$ in which the objective was the minimization of the function of the squared errors between experimental results and model prediction for the set monitored variables.

\section{Results and discussion}


224 The photo-Fenton model developed in this study considers $\mathrm{Fe}(\mathrm{III})$ as the most 225 predominant photon absorbing species in solution. This is since $\mathrm{H}_{2} \mathrm{O}_{2}$ and Fe (II) do not 226 absorb above $300 \mathrm{~nm}$, while the contaminant and the transformation products exhibited negligible absorption compared with Fe(III). Figure 3 compares the absorbance of the species in solution during the photo-Fenton reaction of paracetamol (8.33 mM TOC, $0.36 \mathrm{mM} \mathrm{Fe}(\mathrm{II}), 35.3 \mathrm{mM} \mathrm{H} \mathrm{O}_{2}$ and $46 \mathrm{~W} \cdot \mathrm{m}^{-2}$ of UV irradiance) at different reaction times and the absorbance of an acidified Fe(III) solution in pure water at equal concentration $(0.36 \mathrm{mM})$. The evolution of the absorption spectra during the reaction was found to vary little, as long as the photo-Fenton cycle was operative and hydrogen peroxide was present in the reaction system. During the first 30 min the absorption spectra of the water resembled the absorption spectra of Fe(III) although the intensity was lower. At around 45 min a greater fraction of $\mathrm{Fe}(\mathrm{III})$ was transformed to $\mathrm{Fe}(\mathrm{II})$ while the contaminant was almost removed. Finally, when the decontamination process was complete and the $\mathrm{H}_{2} \mathrm{O}_{2}$ had been consumed, the residual $\mathrm{Fe}(\mathrm{III})$ was photochemically reduced to $\mathrm{Fe}(\mathrm{II})$ and the absorption spectra of the water changed to reflect the absorption spectra of $\mathrm{Fe}(\mathrm{II})$ alone.

It was observed that the absorption spectra during this experiment were always lower than those expected from a pure Fe(III) aqueous solution. This effect is related to the transformation of a small fraction of $\mathrm{Fe}(\mathrm{III})$ to the non-absorbing $\mathrm{Fe}(\mathrm{II})$ during the catalytic iron cycle. Thus, the results show that Fe(III) is the predominant absorbing species during the photo-Fenton oxidation reaction and that other compounds in solution are not interfering in the absortion of photons.

Figure 4 shows the results of oxidation of paracetamol as the model pollutant $(8.33 \mathrm{mM}$ TOC), with $0.36 \mathrm{mM}$ iron concentration, $32 \mathrm{~W} \mathrm{~m}^{-2}$ irradiance and varying the $\mathrm{R}_{\mathrm{i}}$ ratio at 0.30, 0.45 and 0.65 . The initial hydrogen peroxide concentrations were 17.6 and 26.5 $\mathrm{mM}$. This experimental conditions were selected in order to determine the effect of the illuminated reactor volume fraction on the observed reaction kinetics and subsequently, to check the correlation between model predictions and experimental results (TOC, $\mathrm{H}_{2} \mathrm{O}_{2}$ and $\mathrm{O}_{2}$ ). Higher irradiated reactor volumes, at fixed $\mathrm{H}_{2} \mathrm{O}_{2}$ concentration, resulted in higher rates of TOC mineralization and $\mathrm{H}_{2} \mathrm{O}_{2}$ consumption, although the final mineralization efficiency was similar in all cases. In contrast, when the $R_{i}$ ratio was kept constant, the final mineralization percentages were $65 \%$ and $70 \%$ respectively, when the 
257 requirement for complete oxidation of the initial TOC) to $26.5 \mathrm{mM}$ (1.5 times the 258 stoichiometric requirement). Since hydrogen peroxide is also consumed in the 259 inefficient oxygen generating reaction (Reaction 3, Table 1) and considering that not all 260 the radicals produced are utilized to oxidize organic matter (see Reaction 4) [15], a $261 \mathrm{H}_{2} \mathrm{O}_{2}$ requirement higher than the stoichiometric amount is needed for completing the removal of the TOC, which explains the higher rates observed when $26.5 \mathrm{mM}$ of hydrogen peroxide was used. Regarding the temporal evolution of the dissolved oxygen, 264 initially, its concentration decreases to reach a minimum, which occurs when the oxygen demand for the oxidation the organic matter (Dorfman mechanism) is higher than either the oxygen generated by the Reactions 3 and 4 and the oxygen transferred from the air/water interphase. Note that this stage may be more subdue if the rate of generation of radicals is significant. However, after this stage, the oxygen concentration reverse its trend and rises to reach a maximum, since the consumption of oxygen during the early stages of mineralization halts and radicals generation provided by the photoFenton cycle continues, while hydrogen peroxide is still present in the system. Once hydrogen peroxide is totally consumed (halting also the photo-Fenton reaction) the dissolved oxygen concentration tends to reach the equilibrium concentration with the atmosphere [15].

The kinetic parameters obtained from the fitting of the model to the experimental results of $\mathrm{O}_{2}, \mathrm{H}_{2} \mathrm{O}_{2}$ and TOC concentration profiles at different $R_{i}$ ratios are shown in Table 2. The estimated model parameters are compatible with the fundamentals of the elementary chemical reaction of the photo-Fenton mechanism. The monitoring of the different reaction rates during model simulations pointed out the photochemical reaction (Reaction 2) as the rate limiting step for the entire process. In contrast and as expected, the highest kinetic constant was $\mathrm{k}_{4}$ which involves radical-radical reactions. Other kinetics constants are in agreement with the observed process phenomena. Organic matter reactivity displays a decreasing trend during the treatment and this is reflected by the corresponding kinetics constants values $\left(\mathrm{k}_{6}>\mathrm{k}_{7}>\mathrm{k}_{8}>\mathrm{k}_{9}\right)$. At the beginning of the process, a moderate decrease in the dissolved oxygen concentration is observed due to the Dorfman reaction (Reaction 5), the kinetics constant, $k_{5}$, being considerably lower than the other TOC mineralization constants.

The model was found to fit the temporal profiles of $\mathrm{H}_{2} \mathrm{O}_{2}$ and TOC at different $R_{i}$ ratios with a high degree of accuracy (Figure 5) also providing a good representation of the 
increase and decrease in the concentration of oxygen. The model could accurately predict the TOC mineralization and hydrogen peroxide consumption, although the model under-predicted the consumption of $\mathrm{H}_{2} \mathrm{O}_{2}$ for short reaction times. The model accurately predicted the final mineralization percentage and also the time required to completely consume hydrogen peroxide. In addition, the $\mathrm{O}_{2}$ profiles obtained by the model were representative of the observed photo-Fenton behaviour.

Regarding the water treatment processes in which the photochemical reaction is the rate limiting step, as occurs with the photo-Fenton reaction cycle, the variation of the illuminated volume ratio $\left(R_{i}\right)$ allows its influence on the overall reaction kinetics to be evaluated. Usually, the $R_{i}$ ratio in experimental reactor systems is high enough to neglect the impact of the Fenton reaction in the dark volume. Indeed, interrupting the UV irradiance during the photo-Fenton treatment dramatically slowed down the rate of mineralization and the rate of oxygen generation even under an excess of hydrogen peroxide [16]. Consequently, the accuracy of the model prediction slightly decreased when using low $R_{i}$, although it still exhibited a typical trend of the photo-Fenton reaction. The inclusion of the dark Fenton reaction (data not shown) did not improve the capability of the model prediction to fit the experimental results and so, to follow the parsimony principle, it was not taken into account.

The model was also investigated to predict the effect of varying the reactor geometry, by halving the liquid depth to $2.5 \mathrm{~cm}$ in comparison with the depth of the liquid used during the calibration of the model, which was $5 \mathrm{~cm}$. The reactor volume also was reduced by half to $1 \mathrm{~L}$. The other experimental conditions were $8.33 \mathrm{mM}$ TOC, 26.5 $\mathrm{mM} \mathrm{H} \mathrm{H}_{2} \mathrm{O}_{2}, 32 \mathrm{~W} \mathrm{~m}^{-2}$ of irradiance, $\mathrm{R}_{\mathrm{i}}$ ratio of 0.45 and two iron concentrations, 0.14 and $0.36 \mathrm{mM}$ (Figure 6).

314 One immediate consequence of changing the liquid depth and catalyst concentration is the impact on the reactor optical thickness (Eq. 22):

$\tau=\kappa \cdot C \cdot x$

317 In the experiments performed at an initial catalyst concentration of $0.36 \mathrm{mM}$ and $5 \mathrm{~cm}$ 318 of liquid depth the optical thickness was 2.25, a value situated into the theoretical optimum range for photochemical reactors (1.8-3.4) [25]. In contrast, when the liquid 320 depth was diminished to $2.5 \mathrm{~cm}$, the optical thickness decreased to 1.12 and to 0.43 for 
$3210.36 \mathrm{mM}$ and $0.14 \mathrm{mM}$ of Fe, respectively. The later value is far from the optimal range which points out to a loss of photon absorption efficiency and in consequence to slower contaminant oxidation kinetics. However, the model estimations were in accordance with the experimental results, even when the concentration of iron was lowered to 0.14 $\mathrm{mM}$. Note that the model was calibrated for an iron concentration of $0.36 \mathrm{mM}$. As anticipated, the assay with the lowest iron concentration resulted in a lower rate of mineralization of paracetamol and the lower rate of consumption of hydrogen peroxide was also reflected by the modified $\mathrm{O}_{2}$ evolution profiles. In contrast, final TOC concentrations achieved were the same in both assays suggesting that, under the range studied, the iron concentration did not affect the final mineralization percentage but the degradation rate.

\section{Conclusions}

A photo-Fenton model for organic matter mineralization based on general reactions has been proposed. Although paracetamol has been chosen as the target pollutant for this study, the model can be easily applied to other contaminants or mixtures of contaminants because the oxidation/mineralization steps are based on a lumped parameter represented by the TOC. The effect of the $R_{i}$ ratio over the process kinetics was successfully included in the model meaning that it is possible to use it for scalingup purposes, as noticeable differences regarding $R_{i}$ ratio values normally exist between laboratory, pilot and industrial scales. In addition, the effects of photo-reactor geometry and light absorption were incorporated into the model by means of VRPA. After evaluating the species responsible for photon absorption during the oxidation process mainly Fe(III), the use of VRPA in the model was validated by shortening the reactor optical path length from $5 \mathrm{~cm}$ to $2.5 \mathrm{~cm}$ and varying the catalyst loading. In both cases, the model successfully fitted the experimental data meaning that it would be possible to optimize the process by selecting the most suitable reactor optical path length for a given UV source based solely on model simulations. The dissolved oxygen concentration was considered as a response variable and as an indicator of process efficiency. The model can be used for controlling the Photo-Fenton process by optimizing the dosing of hydrogen peroxide, ultimately leading to a reduction in the operating costs of water treatment process. 


\section{Acknowledgements}

355 This research was supported by the Junta de Andalucía (Andalusian Regional 356 Government) (P10-RNM-05951; P12-RNM-01437) and the European Regional 357 Development Fund (ERDF). Alejandro Cabrera Reina would like to acknowledge the 358 Junta de Andalucía for his postdoc placement.

359

360

\section{Bibliography}

361

362

[1] V. Augugliaro, M. Litter, L. Palmisano, J. Soria, J. Photochem. Photobiol. C 7 363

364 (2006) 127-144.

[2] S. Malato, P. Fernández-Ibáñez, M.I. Maldonado, J. Blanco, W. Gernjak, Catal. Today 147 (2009) 1-59.

366 [3] M.L. Marín, L. Santos-Juanes, A. Arques, A.M. Amat, M.A. Miranda, Chem. Rev. 367

368 112 (2012) 1710-1750.

368

[4] A.G. Agrios, P.Pichat, J. Appl. Electrochem. 35 (2005) 655-663.

369

[5] J.J. Pignatello, E. Oliveros, A. MacKay, Crit. Rev. Env. Sci. Technol. 36 (2006) 1370 84.

[6] J. Soler, A. García-Ripoll, N. Hayek, P. Miró, R. Vicente, A. Arques, A.M. Amat. Water Res. 43 (2009) 4441-4450.

[7] A. Zapata, I. Oller, E. Bizani, J.A. Sánchez-Pérez, M.I. Maldonado, S. Malato. Catal. Today 144 (2009) 94-99.

375 [8] S. Navalon, M. Alvaro, H. Garcia, Appl. Catal. B-Environ. 99 (2010) 1-26.

376 [9] L. Santos-Juanes Jordá, M.M. Ballesteros Martín, E. Ortega Gómez, A. Cabrera 377 Reina, I.M. Román Sánchez, J.L. Casas López, J.A. Sánchez Pérez, J. Hazard. Mater. $378186(2011)$ 1924-1929.

379 [10] De Laat and Giang Le, Env. Sci. Technol. 39 (2005) 1811-1818. 
380 [11] G.B. Ortiz de la Plata, O.M. Alfano, A.E. Cassano, Appl. Catal. B: Environ. 95 381 (2010) 14-25.

382 [12] M. Pérez-Moya, M. Graells, P. Buenestado, H.D. Mansilla, Appl. Catal. B: 383 Environ. 84 (2008) 313-323.

384 [13] S. Mohajeri, H.A. Aziz, M.A. Zahed, L. Mohajeri, M.J.K. Bashir, S.Q. Aziz, M. N. 385 Adlan, M.H. Isa, Water Sci. Technol. 64 (2011) 1652-1660.

386 [14] A. Cabrera Reina, L. Santos-Juanes Jordá, J.L. García Sánchez, J.L. Casas López, 387 J.A. Sánchez Pérez, Appl. Catal. B: Environ. 119-120 (2012) 132-138.

388 [15] L. Santos-Juanes, J.L.G. Sánchez, J.L.C. López, I. Oller, S. Malato, J.A. Sánchez 389 Pérez, Appl. Catal. B: Environ. 104 (2011) 316-323.

390 [16] E. Ortega-Gómez, J.C. Moreno Úbeda, J.D. Álvarez Hervás, J.L. Casas López, L. 391 Santos-Juanes Jordá, J.A. Sánchez Pérez, J. Hazard. Mater. 237-238 (2012) 223-230.

392 [17] L. Prieto-Rodríguez, I. Oller, A. Zapata, A. Agüera, S. Malato, Catal. Today 161 393 (2011) 247-254.

394 [18] J. Farias, E.D. Albizzati, O.M. Alfano, Catal. Today 144 (2009) 117-123.

395 [19] R. Moreno-González, S. Rodríguez-Mozaz, M. Gros, E. Pérez-Cánovas, D. 396 Barceló, V.M. León, Sci. Total Environ. 490 (2014) 59-72.

397 [20] R.F.P. Nogueira, M.C. Oliveira, W.C. Paterlini, Talanta 66 (2005) 86-91.

398 [21] J. Colina-Maìrquez, F. Machuca-Martínez, G.L. Puma, Environ. Sci. Technol. 43 399 (2009) 8953-8960.

400 [22] O.M. Alfano, H.A. Irazoqui, A.E. Cassano, (2009) Photochem. Photobiol. Sci. 8 $401 \quad$ (2009) 1047-1058.

402 [23] L.M. Dorfman, I.A. Taub, R.E. Bühler, J. Chem. Phys. 36 (1962) 3051-3061.

403 [24] A. Cabrera Reina, J.L. Casas López, M.I. Maldonado Rubio, L. Santos-Juanes 404 Jordá, J.L. García Sánchez, J.A. Sánchez Pérez, Chem. Eng. J. 237 (2014) 469-477.

405 [25] G. Li Puma, Environ. Sci. Technol. 37 (2003) 5783-5791. 
407 Table 1. Photo-Fenton reactions, kinetics rate laws and mass balances of the proposed 408 model.

409 Table 2. Kinetics constants obtained after model calibration.

\section{Figure captions:}

412 Figure 1. Experimental setup

413 Figure 2. UV-Vis spectra of Fe(III) solutions at different concentrations

414 Figure 3. Comparison between the absorption spectra of a Fe(III) acidic solution and 415 wastewater samples taken during a photo-Fenton assay

416 Figure 4. TOC mineralization and $\mathrm{H}_{2} \mathrm{O}_{2}$ consumption profiles for the experimental 417 series in which the $R_{i}$ ratio was varied between 0.30 and 0.65 and at two initial 418 hydrogen peroxide concentrations, -left- $26.5 \mathrm{mM}$-right- $17.6 \mathrm{mM}$

419 Figure 5. Comparison between experimental TOC mineralization, $\mathrm{H}_{2} \mathrm{O}_{2}$ consumption 420 and dissolved oxygen profiles and model predictions for the different values of $R_{i}$ ratio 421 (0.65 -left-, 0.45 -centre- and 0.30 -right-) when the initial $\mathrm{H}_{2} \mathrm{O}_{2}$ concentration chosen 422 was $17.6 \mathrm{mM}$

423 Figure 6. Comparison between experimental and simulated profiles using a different 424 solar reactor configuration (2.5 cm of liquid depth) and varying Fe concentration (0.14 425 $\mathrm{mM}$-left- and $0.36 \mathrm{mM}$-right-) 